\title{
FORMULATION AND EVALUATION OF FLURBIPROFEN FAST DISINTEGRATING TABLETS USING NATURAL SUPERDISINTEGRANTS
}

\author{
SARFARAZ MOHAMMED, SURENDRA KUMAR SHARMA, KALPANA KAUCHA, DODDAYYA HIREMATH
}

Department of Pharmaceutics, NET Pharmacy College, Raichur, Karnataka, India. Email: sarfindia@gmail.com

Received: 25 July 2016, Revised and Accepted: 30 July 2016

\section{ABSTRACT}

Objective: The main objective of this research was to formulate the fast disintegrating tablets (FDT's) of flurbiprofen incorporating superdisintegrants, isolated from natural sources such as Plantago ovata (PO) seeds, Lepidium sativum (LS) seeds, and agar-agar (malt agar).

Methods: Superdisintegrants were isolated from their natural sources using reported methods. Swelling index and hydration capacity were determined for the natural superdisintegrants to know their disintegration capacity. The tablet formulations were designed using isolated natural superdisintegrants. The powder blends were evaluated for pre-compressional parameters such as angle of repose, bulk density, tapped density, Carr's index, and Hausner's ratio. FDT's were prepared by direct compression method. The compressed tablets were characterized for post-compression parameters.

Results: All formulations had hardness, friability, weight variation, and drug content within the pharmacopoeial limits. The wetting time was 84-254 seconds, in vitro disintegration time was between 59.2 and 221 seconds, and in vitro drug release was as low as LS1 - $11.80 \%$ to a maximum of P04 - 98.99\% after 4 minutes of study. Among all, optimized formulation was P04, as it showed good wetting time 84 seconds, fastest disintegration time 59.2 seconds, dispersion time 135 seconds, and drug release of $98.99 \%$ within 4 minutes.

Conclusion: Flurbiprofen FDT's were successfully developed using isolated natural disintegrants. The natural disintegrants isolated showed promising results and can prove as effective alternative for synthetic disintegrants.

Keywords: Flurbiprofen, Fast disintegrating tablets, Plantago ovata, Lepidium sativum, Agar-agar.

(C) 2016 The Authors. Published by Innovare Academic Sciences Pvt Ltd. This is an open access article under the CC BY license (http://creativecommons. org/licenses/by/4. 0/) DOI: http://dx.doi.org/10.22159/ajpcr.2016.v9i6.14303

\section{INTRODUCTION}

Fast disintegrating tablets (FDT's) are gaining prominence as new drug delivery systems. These dosage forms dissolve or disintegrate in oral cavity within a minute without the need of water or chewing. FDT's are not only useful in administration of drugs in pediatric and geriatric patients but also in patients suffering from dysphasia and are ideal for active people as well [1,2]. These dosage forms show good stability, ease of manufacture, and ease of handling by patients. Flurbiprofen is a poor water soluble drug $(\mathrm{pKa}=4.42)$ that is available in the market as a non-steroidal anti-inflammatory agent [3]. It is primarily intended to treat painful conditions, which requires fast release of the drug [4] Flurbiprofen is Class II drug and is absorbed at a slower rate from oral route and dissolution rate is the rate limiting step [5]. This makes it difficult for absorption and thereby bioavailability of drug. In the present study, our efforts are toward making a FDT's of flurbiprofen that can increase its solubility and dissolution rate and hence bioavailability of drug. Some of the recent research examples for flurbiprofen fast dissolving systems are flurbiprofen FDT's [6], flurbiprofen fast dissolving tablets [7], and flurbiprofen solid dispersions [8]. It is observed that in most of the research works direct compression is widely used for preparing FDT's. Direct compression is one of the techniques which require incorporation of a superdisintegrant into the formulation, or the use of highly water-soluble excipients to achieve fast tablet disintegration $[9,10]$. FDT's can be prepared using two types of superdisintegrants; natural and synthetic. Compared to synthetic disintegrants; natural superdisintegrants are safer, more biodegradable, better compressible, easier for preparation, and cheaper, and these advantages can boost the production of FDT's [11]. It can be noted from literature survey that most of flurbiprofen FDT's are prepared using synthetic disintegrants. Hence, in the present research, it was aimed to prepare novel flurbiprofen FDT's using natural superdisintegrants, which can increase the solubility and dissolution of the drug and also is safe.

\section{MATERIALS AND METHODS}

Flurbiprofen was obtained as a gift sample from FDC Limited, Mumbai, India. Plantago ovata (PO) and Lepidium sativum (LS) seeds were purchased from local market, Raichur, India. Spray dried mannitol was procured from SPI Pharma, agar-agar, and microbial culture collection were purchased from SD Fine Chemicals Pvt. Ltd., Mumbai, India. Aerosil 200 was obtained from HiMedia Laboratories Pvt. Ltd., Mumbai, India. All other chemicals and reagents used were of pharmaceutical and analytical grade.

Isolation of mucilage from PO seeds

PO seeds (Fig. 1) were soaked in distilled water for $48 \mathrm{hrs}$ and again some more amount of water was added, kept for next $48 \mathrm{hrs}$. Later it was boiled for few minutes for complete release of mucilage into water. The material was squeezed through muslin cloth for filtering and separating out the marc. Then, an equal volume of acetone was added to the filtrate, so as to precipitate the mucilage. The separated mucilage was dried in oven at temperature $<60^{\circ} \mathrm{C}$, powdered, sieved (\#80), and stored in a desiccator until use [12].

\section{Isolation of mucilage from LS seeds}

LS seeds (Fig. 2) contain the mucilage around the outer layer. Mucilage was extracted by soaking the seeds with 10 times of its weight with distilled water and kept for 24 hrs. The viscous solution obtained was passed through 8 -folds of muslin cloth. Then, the mucilage was precipitated well by addition of $95 \%$ ethanol in the ratio $1: 1$ by constant stirring. The coagulated mass was dried in an oven at $40-45^{\circ} \mathrm{C}$ till it was completely dried. The dried powders were grinded by mortar and pestle. The powder was passed through 80 mesh (\#) and stored in dessicator [13].

\section{Preparation of modified agar}

Suitable quantity of agar powder (Fig. 3) (5-10 g) is weighed and added in distilled water $(100 \mathrm{ml})$. Agitation is done continuously by magnetic 
stirrer for $24 \mathrm{hrs}$ to swell. The swollen contents are dried on a tray for three-dimensions at room temperature. The dried powders are grinded by mortar and pestle and passed through 80 mesh (\#) collected and stored in dessicator [14]

Characterization of dried isolated mucilages/prepared natural super disintegrants

Swelling index (SI) of superdisintegrants

The isolated/prepared natural superdisintegrants $(1 \mathrm{~g})$ were taken in separate measuring cylinders. Then, distilled water $(100 \mathrm{ml})$ was poured in them separately. The measuring cylinder was shake vigorously for 10 minutes and allowed to stand for $24 \mathrm{hrs}$ at $37 \pm 0.5^{\circ} \mathrm{C}$ The experiment was carried out in triplicate and mean was taken.

Swelling capacity was expressed as percentage and calculated using following formula:

Swelling capacity $(\%)=(\mathrm{Xv} / \mathrm{Xi}) \times 100$

Where,

$\mathrm{Xv}=$ Final volume occupied by swollen material after $24 \mathrm{hrs}$.

$\mathrm{Xi}=$ Initial volume occupied by powder in measuring cylinder.

$$
\text { SI }(\%)=\frac{\text { Final volume }- \text { Initial volume }}{\text { Initial volume }} \times 100
$$

The swollen mass from measuring cylinder, at the end of test period was removed and weighed (g) to get the final weight and percentage increase in weight was determined by using the following equation.

Increase in weight $(\%)=\frac{\text { Final weight }- \text { Initial weight }}{\text { Initial weight }} \times 100$

Percentage increase in weight was used to interpret water uptake capacity of the supedisintegrants [15].

\section{Hydration capacity (HC) of superdisintegrants}

The isolated/prepared natural superdisintegrants $(1 \mathrm{~g})$ were taken in the three different $15 \mathrm{ml}$ tarred centrifuge tubes. Then, $10 \mathrm{ml}$ of distilled water was added to each centrifuge tube and allowed to centrifuge for 2 hrs at $3000 \mathrm{rpm}$. After the centrifugation process, the tarred centrifuge tube was taken out and inverted to remove the supernatant liquid [16] The decanted tube then weighed on digital balance and the HC was calculated using the following equation.

HC=Weight of hydrate sample/weight of dry sample.

The experiment was carried out in triplicate and mean was taken.

\section{Preformulation studies}

Fourier transform infrared spectroscopy (FT-IR) study

The compatibility between pure drug and excipients was detected by FT-IR spectra obtained on comp-Bruker, model alpha-T, (USA). The pellets were prepared on $\mathrm{KBr}$ press. The spectra were recorded over the wave number range of $4000-500 \mathrm{~cm}^{-1}$ for pure flurbiprofen and $3500-500 \mathrm{~cm}^{-1}$ for flurbiprofen FDT.

\section{Differential scanning calorimeter (DSC) studies}

Thermograms of pure flurbiprofen and its formulation were obtained by using DSC (Mettler Star SW 8.10 ) at a heating rate $10^{\circ} \mathrm{C} /$ minutes over a temperature range of $35-300^{\circ} \mathrm{C}$. Accurately weighed $2.0 \mathrm{mg}$ of the sample was hermetically sealed in an aluminum pan. Nitrogen gas was purged at rate of $10 \mathrm{ml} /$ minutes for maintaining inert atmosphere.

\section{Preparation of flurbiprofen FDT's}

FDT's of flurbiprofen were prepared using direct compression method. All the ingredients were taken in sufficient quantity and passed through

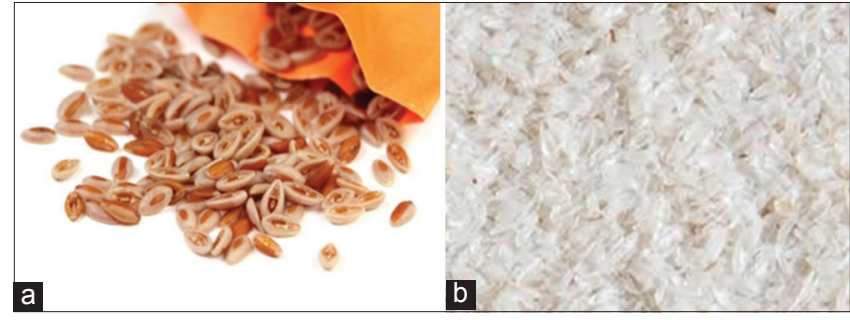

Fig. 1: Plantago ovata seeds (a) and husk (b)

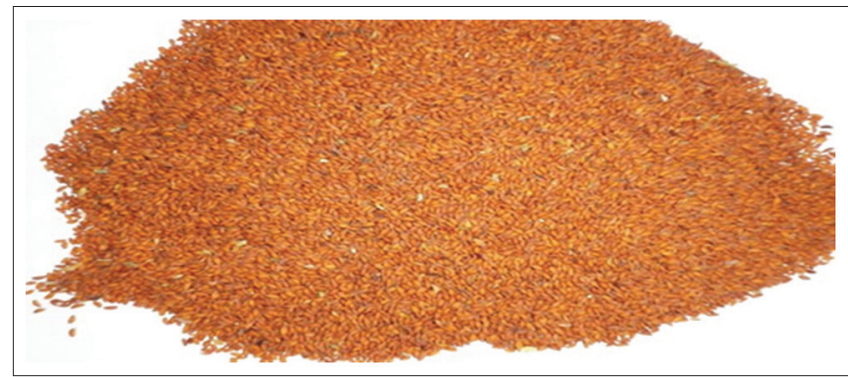

Fig. 2: Lepidium sativum seeds

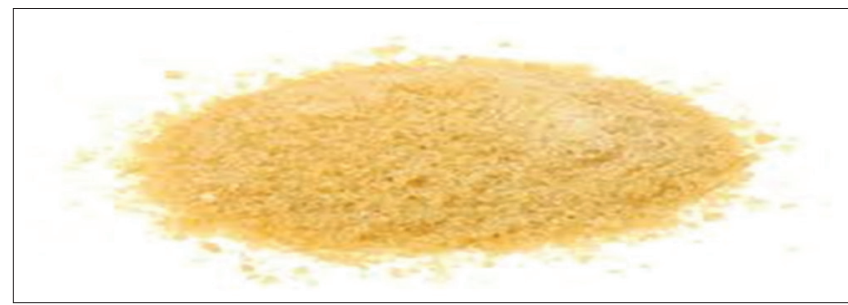

Fig. 3: Agar-agar powder

sieve number 80 . The natural superdisintegrants PO, LS and modified agar were used in concentrations of $2 \%, 4 \%, 6 \%$, and $8 \%$ to formulate the tablets. All the ingredients as shown in Table 1 were co-ground in a pestle and motor and then magnesium stearate and talc were added and mixed for 10 minutes. The mixed blend of drug excipients was compressed using 10 stations compression machine to produce tablets.

\section{Pre-compression evaluation of flurbiprofen FDT formulations} Angle of repose

Angle of repose $(\alpha)$ was determined using funnel method. The blend was poured through a funnel that can be raised vertically until a maximum cone height $(\mathrm{H})$ was obtained. The radius of the heap $(\mathrm{r})$ was measured and angle of repose was calculated [17]. $\alpha=\tan ^{-1}(H / r)$. The experiment was carried out in triplicate and mean \pm standard deviation (SD) values were taken.

\section{Bulk density}

Apparent bulk density ( $\rho$ b) was determined by placing perceived drug excipients blend in to a graduated cylinder and measuring the volume $(\mathrm{Vb})$ and weight $(\mathrm{M})$ "as it is." $\rho b=\mathrm{M} / \mathrm{Vb}$.

\section{Tapped density}

The measuring cylinder containing a known mass of blend was tapped for a fixed number of taps. The minimum volume (Vt) occupied in the cylinder and weight (M) of the blend was measured [18]. The tapped density $(\rho t)$ was calculated using the following formula:

$\rho \mathrm{t}=\mathrm{M} / \mathrm{Vt}$

The experiment was carried out in triplicate and mean $\pm S D$ values were taken. 
Table 1: Composition of flurbiprofen fast disintegrating tablets

\begin{tabular}{|c|c|c|c|c|c|c|c|c|c|c|c|c|}
\hline Ingredients & $\begin{array}{l}\text { P01 } \\
\text { (mg) }\end{array}$ & $\begin{array}{l}\text { P02 } \\
\text { (mg) }\end{array}$ & $\begin{array}{l}\text { P03 } \\
\text { (mg) }\end{array}$ & $\begin{array}{l}\text { P04 } \\
\text { (mg) }\end{array}$ & $\begin{array}{l}\text { LS1 } \\
\text { (mg) }\end{array}$ & $\begin{array}{l}\text { LS2 } \\
\text { (mg) }\end{array}$ & $\begin{array}{l}\text { LS3 } \\
\text { (mg) }\end{array}$ & $\begin{array}{l}\text { LS4 } \\
\text { (mg) }\end{array}$ & $\begin{array}{l}\text { MA1 } \\
\text { (mg) }\end{array}$ & $\begin{array}{l}\text { MA2 } \\
\text { (mg) }\end{array}$ & $\begin{array}{l}\text { MA3 } \\
\text { (mg) }\end{array}$ & $\begin{array}{l}\text { MA4 } \\
\text { (mg) }\end{array}$ \\
\hline Flurbiprofen & 50 & 50 & 50 & 50 & 50 & 50 & 50 & 50 & 50 & 50 & 50 & 50 \\
\hline $\begin{array}{l}\text { Microcrystalline } \\
\text { cellulose }\end{array}$ & 101 & 101 & 101 & 101 & 101 & 101 & 101 & 101 & 101 & 101 & 101 & 101 \\
\hline Spray dried mannitol & 40 & 36 & 32 & 28 & 40 & 36 & 32 & 28 & 40 & 36 & 32 & 28 \\
\hline Plantago ovata & 4 & 8 & 12 & 16 & - & - & - & - & - & - & - & - \\
\hline Lepidium sativum & - & - & - & - & 4 & 8 & 12 & 16 & - & - & - & - \\
\hline Aerosil 200 & 1 & 1 & 1 & 1 & 1 & 1 & 1 & 1 & 1 & 1 & 1 & 1 \\
\hline Magnesium stearate & 2 & 2 & 2 & 2 & 2 & 2 & 2 & 2 & 2 & 2 & 2 & 2 \\
\hline Talc & 2 & 2 & 2 & 2 & 2 & 2 & 2 & 2 & 2 & 2 & 2 & 2 \\
\hline
\end{tabular}

P01-P04, LS1-LS4, MA1-MA4 are formulation codes

\section{Compressibility index (Carr's Index)}

Compressibility, an indication of the ease with which a material can be induced to flow, is given by \% compressibility which is calculated as follows:

Carr's index $=(\rho t-\rho b) \times 100 / \rho t$

Where, $\rho \mathrm{t}$ - Tapped density, $\rho \mathrm{b}$ - Untapped bulk density.

\section{Hausner's ratio}

Hausner's ratio is an index of ease of powder flow [19]; it is calculated by the following formula:

Hausner's ratio $=\rho t \backslash \rho b$

pt - Tapped density, $\rho b$ - Untapped bulk density.

\section{Post-compression evaluation of flurbiprofen FDT's}

Thickness and diameter

The thickness and diameter of 10 prepared tablets were measured using Vernier Caliper. The readings were collected three times and mean $\pm \mathrm{SD}$ values were calculated. The result was expressed in millimeter

\section{Hardness}

Hardness was determined by using a Pfizer hardness tester, taking 10 tablets from each formulation, and the average of applied pressure $\left(\mathrm{kg} / \mathrm{cm}^{2}\right)$ for crushing the tablet was determined [20]. From the average, $\mathrm{SD}$ values was calculated.

\section{Friability}

Friability test was performed by using Roche friabilator. 10 tablets were weighed and placed in the friabilator, which was then operated for 25 revolutions/minutes (rpm). After 4 minutes (100 rpm), the tablets were dedusted and reweighed. The percentage friability was determined [21]. The test was performed thrice, and the mean \pm SD values were calculated.

\section{Weight variation}

About 20 tablets were randomly selected and individually weighed. The average weight of tablets was calculated. Then, the individual weight was compared with that of average weight and the amount of weight variation was determined [22].

\section{Dispersion time}

One tablet was placed in a beaker containing $100 \mathrm{ml}$ of $\mathrm{pH} 6.8$ phosphate buffer at $37 \pm 0.5^{\circ} \mathrm{C}$ and the time required for complete dispersion was determined. The resulting dispersion was passed through sieve number 22 [23]. The procedure was repeated thrice, and the mean \pm SD values were calculated.

\section{Drug content}

For estimation of drug content, 10 tablets were crushed, and the aliquot of powder equivalent to $50 \mathrm{mg}$ of drug was extracted in methanol/ phosphate buffer $\mathrm{pH} 6.8$, suitably diluted using phosphate buffer $\mathrm{pH} 6.8$ and determined by ultraviolet-visible spectrophotometer at $247 \mathrm{~nm}$. Three powder samples were used to determine drug content, and the mean was derived from them. The drug content was calculated from the calibration curve [24].

\section{Wetting time}

A piece of tissue paper $(12 \times 10.75 \mathrm{~cm})$ folded twice was placed in a Petri dish containing $6 \mathrm{ml}$ of water. A tablet was placed on the paper and the time taken for complete wetting of tablet was noted. Three tablets from each formulation were randomly selected and the average wetting time in s was noted.

\section{Water absorption ratio}

A piece of tissue paper folded twice was placed in a small Petri dish containing $6 \mathrm{ml}$ of water. A tablet was put on the paper and the time required for complete wetting was measured. The wetted tablet was then weighed. Water absorption ratio was determined [25]. The test was performed thrice and mean was calculated.

\section{In vitro disintegration time}

The test was carried out in a disintegration test apparatus using distilled water as disintegration medium at $37 \pm 0.5^{\circ} \mathrm{C}$. A tablet was placed in each of six tubes of the apparatus and one disc was added to each tube. The time taken for complete disintegration of the tablet with no mass remaining in the apparatus was measured.

\section{In vitro dissolution study}

In vitro dissolution study was carried out using USP apparatus Type II (Paddle type). The dissolution medium used was $\mathrm{pH} 6.8$ phosphate buffer $(900 \mathrm{ml})$ maintained at temperature $37 \pm 5^{\circ} \mathrm{C}$ at $75 \mathrm{rpm}$. About $5 \mathrm{ml}$ sample was withdrawn periodically and replaced with same volume of fresh medium. Absorbance of the solution was measured at $247 \mathrm{~nm}[26]$.

\section{Stability study}

The Stability study of flurbiprofen FDT P04 was carried out at $40 \pm 2^{\circ} \mathrm{C} / 75 \pm 5 \% \mathrm{RH}$ for 6 month by storing in stability chamber and analyzed periodically at intervals of 1 month.

\section{RESULTS AND DISCUSSION}

Isolation of the mucilages/natural superdisintegrants was carried out from PO seeds, LS seeds, and agar-agar. The obtained dried powders were tested for SI and HC. The results are given in Figs. 4 and 5.

Superdisintegrants are generally used at low level, typically $1-10 \%$ by weight relative to the total weight of the dosage unit. Swelling and HC are the important parameters for comparing disintegration efficiency. 
Generally, it is considered that higher the swelling and HC better the disintegration. PO was found to have higher SI and $\mathrm{HC}$ as it swells to a large extent in contact with water. In this study, it was observed that $S$ of PO was found higher than LS and malt agar (MA). PO because of its gelling and viscous property has higher SI than other disintegrants. The order of $\mathrm{SI}$ and $\mathrm{HC}$ was $\mathrm{PO}>\mathrm{LS}>\mathrm{MA}$.

\section{Preformulation studies}

\section{FT-IR spectral study}

The comparative FT-IR spectral study of pure drug and formulation P04 (drug with excipients) reveals the fact that there is no marked shift in the position of characteristic absorption band of the functional group and bonds present in the drug molecule. Hence, it may be concluded that there is no interaction of the drug with natural excipients. Figs. 6 and 7 represent the FT-IR spectra of pure drug and formulation P04.

\section{DSC studies}

The thermograms revealed no significant change in the nature and height of the peak of drug molecule in both the graphs, suggesting that the drug has remained in its normal form without undergoing any interaction with natural excipients. Hence, it was concluded that there is no interaction of the drug with excipients of formulation. Figs. 8 and 9 represent the DSC thermograms of pure drug and formulation PO4, respectively.

\section{Precompression evaluation of flurbiprofen FDT powder blend}

For each formulation, blend of drug and excipients were evaluated for micromeritic properties. Angle of repose was found to be in the

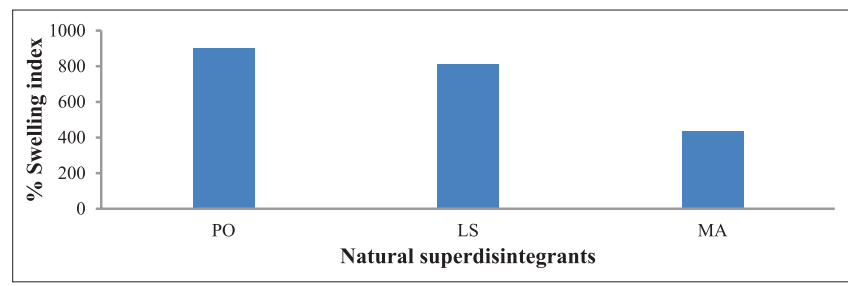

Fig. 4: Swelling index of natural superdisintegrants. The data represent mean of three determinations

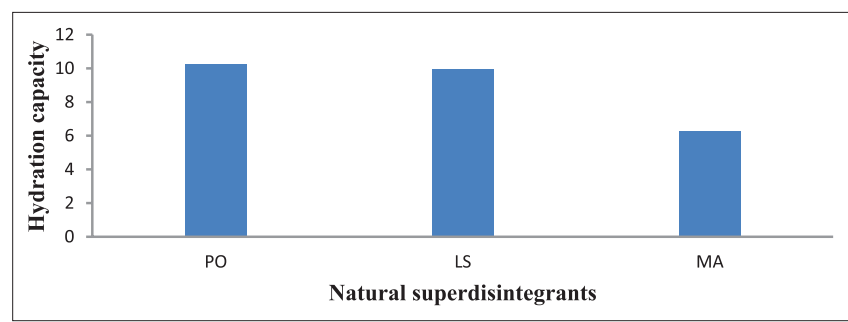

Fig. 5: Hydration capacity of natural superdisintegrants. The data represent mean of three determinations range of $25.03 \pm 0.16-37.30 \pm 0.24$. The bulk density was found to be between $0.32 \pm 0.06$ and $0.33 \pm 0.0 .20 \mathrm{~g} / \mathrm{cm}^{3}$ and tapped density between $0.39 \pm 0.44$ and $0.41 \pm 0.08 \mathrm{~g} / \mathrm{cm}^{3}$ for all formulations. From density data, Carr's index was calculated and was found to be between $15.38 \% \pm 0.14 \%$ and $21.22 \% \pm 0.26 \%$. Hausner ratio was found below $1.18 \pm 0.06$. All the parameters showed good flow, compression, and blend properties for direct compression and hence tablets were prepared by direct compression method.

\section{Post-compression evaluation of flurbiprofen FDT's}

The post-compression evaluation of flurbiprofen FDT's is given in Tables 2 and 3

The post-compression evaluation was carried out for all 12 formulations developed. It was observed that the thickness of tablets was found in the range of $4.62 \pm 0.90-4.88 \pm 0.78 \mathrm{~mm}$. Diameter of all tablets was between $7.00 \pm 0.65$ and $7.10 \pm 0.44 \mathrm{~mm}$. The hardness of the prepared tablets was maintained within the range of $4.20 \pm 1.41-5.84 \pm 0.58 \mathrm{~kg} / \mathrm{cm}^{2}$; it was considered adequate for mechanical stability, while manufacturing and handling the dosage form. The friability of all formulations was found to be $<1 \%$ and was in the range of $0.07 \pm 0.45-0.45 \pm 1.22 \%$ indicating a good mechanical strength of tablets. The average weight of all compressed tablets was in the range 190-196 mg. All the tablets passed weight variation test as the $\%$ deviation was $<7.5 \%$ as allowed in the pharmacopoeia [27]. The dispersion time is used as an indication for the ease of tablet disintegration. It was found in the range of $2.25 \pm 1.88$ $35.7 \pm 1.74$ minutes. The drug content uniformity was in the range of $97.6 \pm 1.64-99.8 \pm 0.81 \%$.

Since the dissolution process of a tablet depends upon the wetting followed by disintegration of the tablet, the measurement of wetting time may be used as another confirmative test for the evaluation of fast disintegrating tablets [28].Wetting time is closely related to the inner structure of the tablet. The wetting time was in between $84 \pm 1.74$ and $650 \pm 2.49$ seconds for all FDTs. It was observed that the wetting time was least for formulations prepared with PO and highest with LS formulations (Fig. 10). Promising formulation P04 showed a wetting time of 84 seconds, which facilitates faster dispersion of tablet in mouth. The wetting time decreased with increasing superdisintegrant concentration for all the superdisintegrants used. The wetting times of tablets were in the order of $\mathrm{PO}<\mathrm{MA}<\mathrm{LS}$.

\section{In vitro disintegration time}

The in vitro disintegration time was measured by the time taken by the FDT's to undergo complete disintegration. The FDT's prepared with PO P01-P04 disintegrated in $92.83 \pm 0.71,68.2 \pm 0.96,62.67 \pm 1.04$, and $59.17 \pm 1.08$ seconds, respectively. The FDT's prepared with LS LS1-LS4, disintegrated in $221.7 \pm 1.24,209 \pm 1.36,172.8 \pm 0.74$, and $122.5 \pm 0.94$ seconds, respectively, whereas FDT's with modified agar MA1-MA4 disintegrated in $109 \pm 1.54,91.33 \pm 1.84,72 \pm 1.98$, and 61.67 \pm 2.34 seconds (Fig. 10). Formulations PO4 showed rapid disintegration compared to other formulations. The faster disintegration of tablets with PO is due to easy swelling ability and pronounced

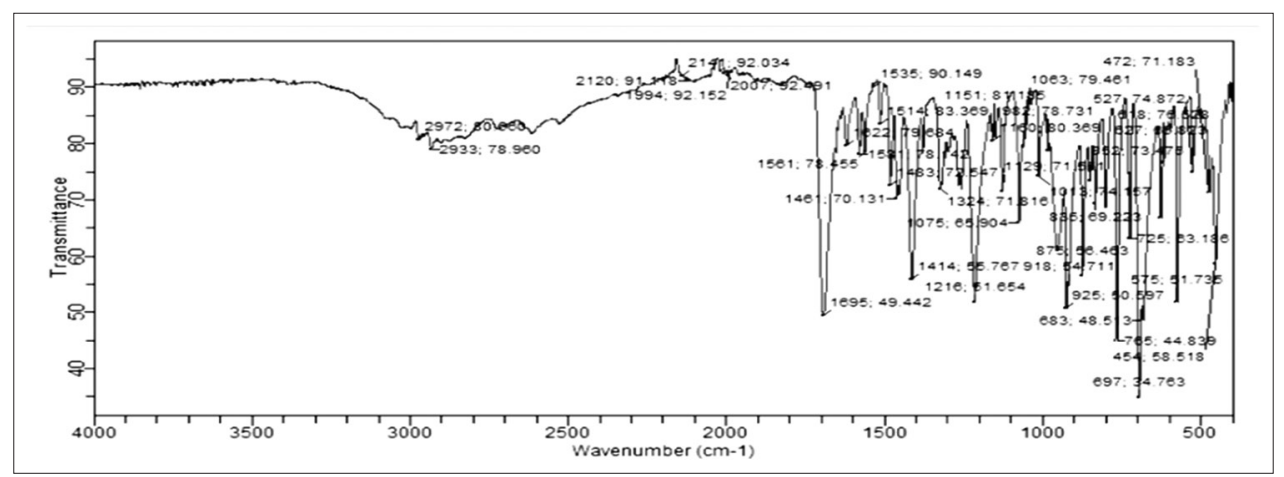

Fig. 6: Fourier transform infrared spectroscopy of pure flurbiprofen drug 


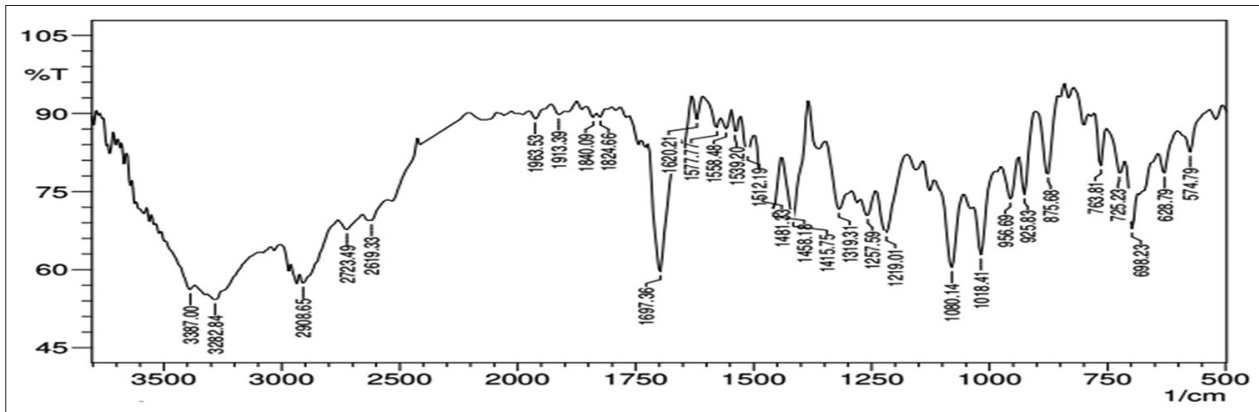

Fig. 7: Fourier transform infrared spectroscopy of flurbiprofen fast disintegrating tablets Plantago ovata 4

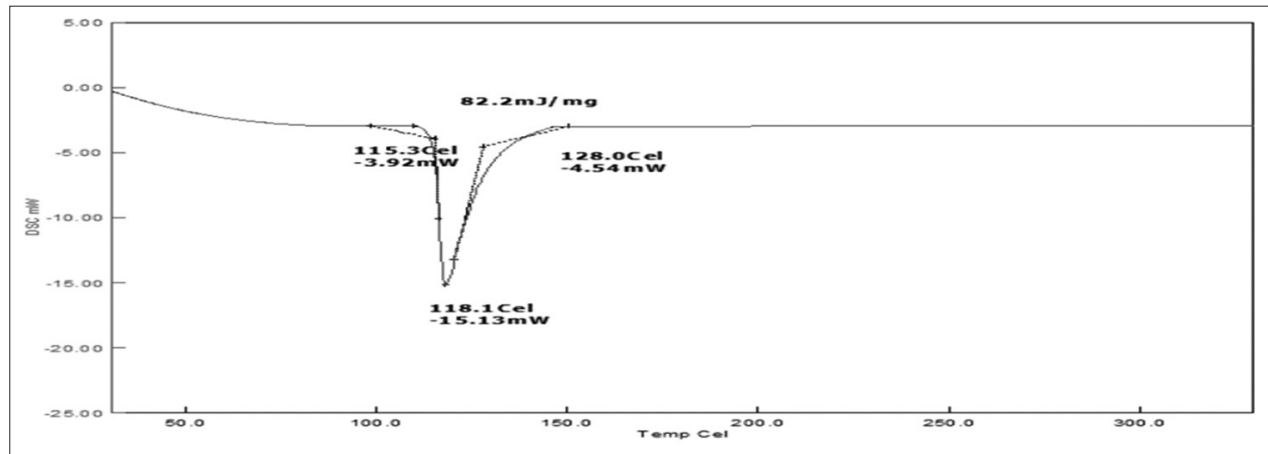

Fig. 8: Differential scanning calorimeter thermogram of pure flurbiprofen drug

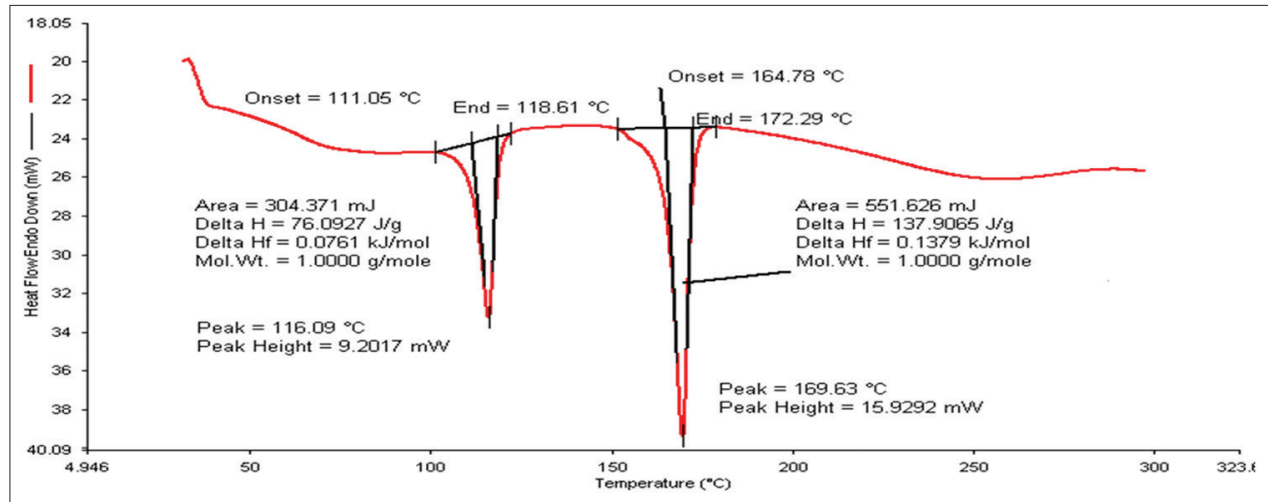

Fig. 9: Differential scanning calorimeter thermogram of flurbiprofen fast disintegrating tablets Plantago ovate 4

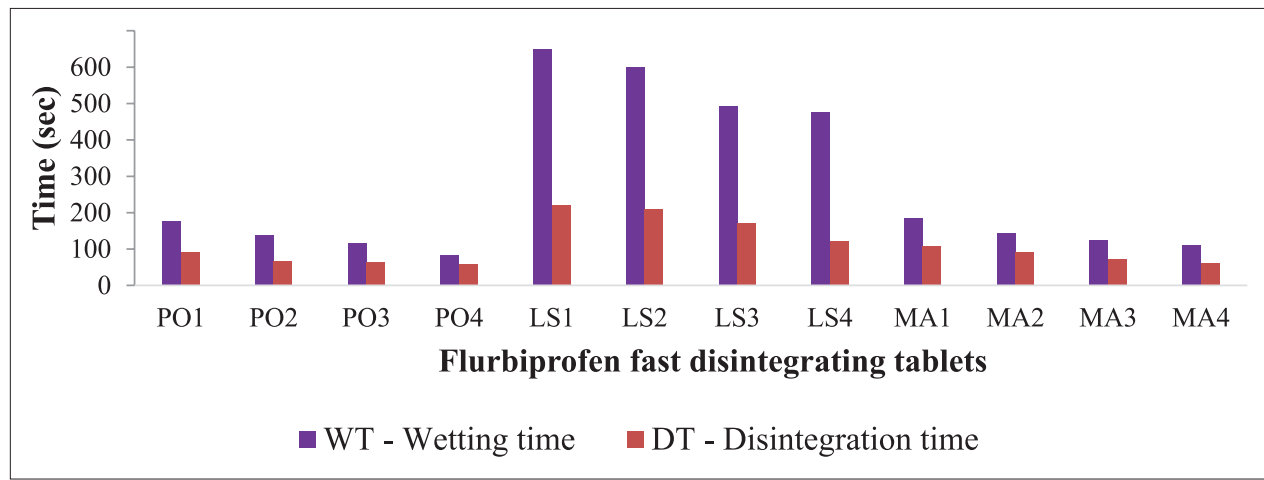

Fig. 10: In vitro disintegration time and wetting time of flurbiprofen fast disintegrating tablets. The data represent mean \pm standard of three determinations

hydration of PO $[29,30]$. The FDT's with LS disintegrated rather slowly. This might be due to LS gelling nature. The water absorption and wetting of tablet takes more time because of its relatively high viscosity and pseudoplasticity. MA consists of two polysaccharides as agarose and agaropectin. Agarose is responsible for gel strength and Agaropectin is responsible for the viscosity of agar solutions [31]. The tablets with 
MA disintegrated faster than LS. Comparatively, the disintegration times of tablets were in the order of $\mathrm{PO}<\mathrm{MA}<\mathrm{LS}$. The results of in vitro disintegration time were in accordance with wetting time studies. It is interesting to note that though LS is having higher swelling and HC than MA; its wetting time is less compared to MA because it is more viscous and jelly than MA. It was observed that as the concentration of superdisintegrants increased from $2 \%$ to $8 \% \mathrm{w} / \mathrm{w}$, the disintegration time reduced considerably. It was observed that all formulations satisfied the disintegration time criteria of fast dissolving tablets.

Water absorption ratio, which is important criteria for understanding the capacity of disintegrants to swell in the presence of little amount of water, was calculated [32]. It was found to be in the range of $101 \pm 1.76-119 \pm 1.65 \%$ (Fig. 11). Water absorption ratio was influenced by disintegrant concentration. The water absorbing power of the disintegrant increased with increase in disintegrant concentration. As observed in wetting time studies, the water absorption ratio of different disintegrants used was in the order $\mathrm{PO}>\mathrm{MA}>\mathrm{LS}$. It is seen that there is a direct correlation between the wetting time studies, disintegration time, and water absorption ratio. The disintegrants with higher water absorbing property have less wetting time and hence minimum disintegration time.

\section{In vitro dissolution study}

The in vitro dissolution of flurbiprofen FDT's was studied in phosphate buffer of pH 6.8 using USP XXIV dissolution test apparatus by paddle method. The release of the drug from the formulated tablets was rapid and complete with all the disintegrants used. The dissolution profiles of tablet containing PO, LS, and modified agar were in agreement with disintegration time results. It was observed that as the concentration of superdisintegrants increased from $2 \%$ to $8 \% \mathrm{w} / \mathrm{w}$ the release of the drug was also increased. The optimized formulation P04 released $98.98 \%$ of drug in 4 minutes. The investigated superdisintegrants based on overall in vitro release profile can be ranked as PO >modified agar >LS. The dissolution profiles of all the FDT's are shown in Figs. 12-15. The FDT's P01-P04 released $72.40-98.98 \%$ of drug in 4 minutes study Fig. 12. Similarly, the FDT's LS1-LS4 released 11.80 $19.63 \%$ of drug in 4 minutes (Fig. 13). The FDT's MA1-MA4 released 48.76-83.75\% of drug in 4 minutes study (Fig. 14).

The FDT's prepared with PO and Modified agar released the drug rapidly compared to tablets with LS. This is due to higher wetting and faster disintegrating property of the disintegrants PO and MA Though the in vitro dissolution study was carried out for a total of 15-25 minutes for all formulations, 4 minutes data have been presented because the optimized tablet P04 released almost $98.98 \%$ of drug in the same period. From the results, it could be concluded that natural superdisintegrants under study can be selected as suitable alternative to their synthetic counterparts, with added advantage of being safe and cheaper. Among the formulations, PO4 containing 8\% PO was found to be optimized, as it showed good hardness, least weight variation, optimum friability, least wetting time, least disintegration time, more water absorption ratio, and maximum and complete drug release rapidly which is an ideal characteristic of a FDT (Fig. 15).

Table 2: Post-compression evaluation of flurbiprofen FDT's prepared using PO and LS

\begin{tabular}{|c|c|c|c|c|c|c|c|c|}
\hline Parameters* & P01* & PO2* & P03* & P04* & LS1* & LS2* & LS3* & LS4* \\
\hline Thickness (mm) & $4.68 \pm 0.91$ & $4.66 \pm 0.88$ & $4.62 \pm 0.90$ & $4.68 \pm 0.78$ & $4.76 \pm 0.65$ & $4.88 \pm 0.78$ & $4.68 \pm 0.91$ & $4.68 \pm 0.82$ \\
\hline Diameter (mm) & $7.10 \pm 0.79$ & $7.06 \pm 0.91$ & $7.08 \pm 0.98$ & $7.10 \pm 0.54$ & $7.00 \pm 0.65$ & $7.04 \pm 0.62$ & $7.10 \pm 0.64$ & $7.10 \pm 0.86$ \\
\hline Hardness $\left(\mathrm{kg} / \mathrm{cm}^{2}\right)$ & $5.34 \pm 0.76$ & $4.80 \pm 0.84$ & $4.20 \pm 1.41$ & $5.04 \pm 1.20$ & $5.84 \pm 0.58$ & $5.16 \pm 0.64$ & $5.48 \pm 1.78$ & $5.40 \pm 1.44$ \\
\hline Friability (\%) & $0.07 \pm 0.45$ & $0.12 \pm 0.76$ & $0.19 \pm 0.65$ & $0.31 \pm 0.91$ & $0.34 \pm 0.98$ & $0.45 \pm 1.22$ & $0.28 \pm 1.66$ & $0.30 \pm 0.84$ \\
\hline Weight variation $(\%)$ & $2.30 \pm 0.84$ & $2.40 \pm 0.78$ & $2.10 \pm 0.86$ & $2.50 \pm 1.56$ & $3.10 \pm 1.82$ & $2.40 \pm 1.61$ & $3.20 \pm 0.88$ & $2.30 \pm 0.76$ \\
\hline Dispersion time (min) & $5.50 \pm 1.92$ & $4.01 \pm 1.68$ & $3.00 \pm 2.02$ & $2.25 \pm 1.88$ & $35.7 \pm 1.74$ & $29.9 \pm 1.24$ & $20.45 \pm 1.90$ & $14.95 \pm 1.82$ \\
\hline Drug content (\%) & $99.8 \pm 0.81$ & $98.6 \pm 0.65$ & $99.0 \pm 2.10$ & $99.0 \pm 0.79$ & $98.6 \pm 0.65$ & $98.2 \pm 0.88$ & $98.8 \pm 1.25$ & $97.6 \pm 1.32$ \\
\hline
\end{tabular}

*Values represented as mean \pm SD (n=3). SD: Standard deviation, FDT's: Fast disintegrating tablets, PO: Plantago ovate, LS: Lepidium sativum

Table 3: Post-compression evaluation of flurbiprofen FDT's prepared using MA

\begin{tabular}{lllr}
\hline Parameters & MA1* & MA2* & MA3* \\
\hline Thickness (mm) & $4.68 \pm 0.66$ & $4.70 \pm 0.92$ & $4.70 \pm 0.84$ \\
Diameter (mm) & $7.10 \pm 0.44$ & $7.10 \pm 0.26$ & $7.08 \pm 0.60$ \\
Hardness (kg/cm ${ }^{2}$ ) & $4.88 \pm 1.90$ & $5.24 \pm 1.02$ & $4.66 \pm 0.76$ \\
Friability (\%) & $0.20 \pm 0.54$ & $0.18 \pm 0.68$ & $7.10 \pm 0.78$ \\
Weight variation (\%) & $3.20 \pm 1.50$ & $5.10 \pm 0.80$ & $0.18 \pm 0.80$ \\
Dispersion time (minutes) & $7.07 \pm 1.34$ & $5.00 \pm 1.72$ & $3.60 \pm 2.92$ \\
Drug content (\%) & $98.8 \pm 0.76$ & $97.6 \pm 1.64$ & $3.75 \pm 1.62$ \\
\hline
\end{tabular}

*Values represented as mean \pm SD (n=3). SD: Standard deviation, FDT's: Fast disintegrating tablets, MA: Malt agar

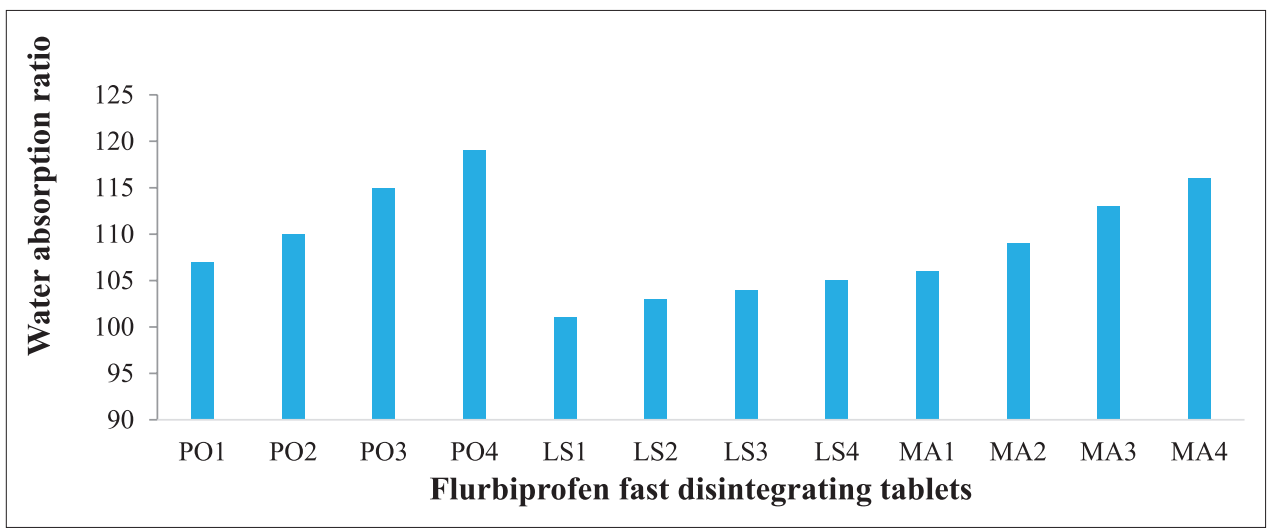

Fig. 11: Water absorption ratio of flurbiprofen fast disintegrating tablets. The data represent mean \pm standard of three determinations 


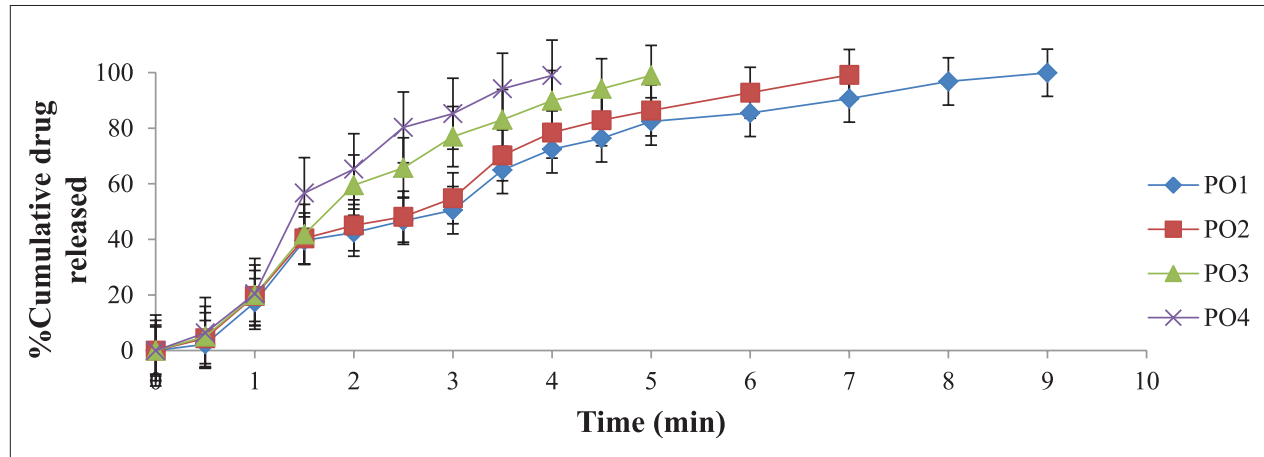

Fig. 12: In vitro dissolution profile of fast disintegrating tablet's prepared using Plantago ovata. The data represent mean \pm standard of three determinations

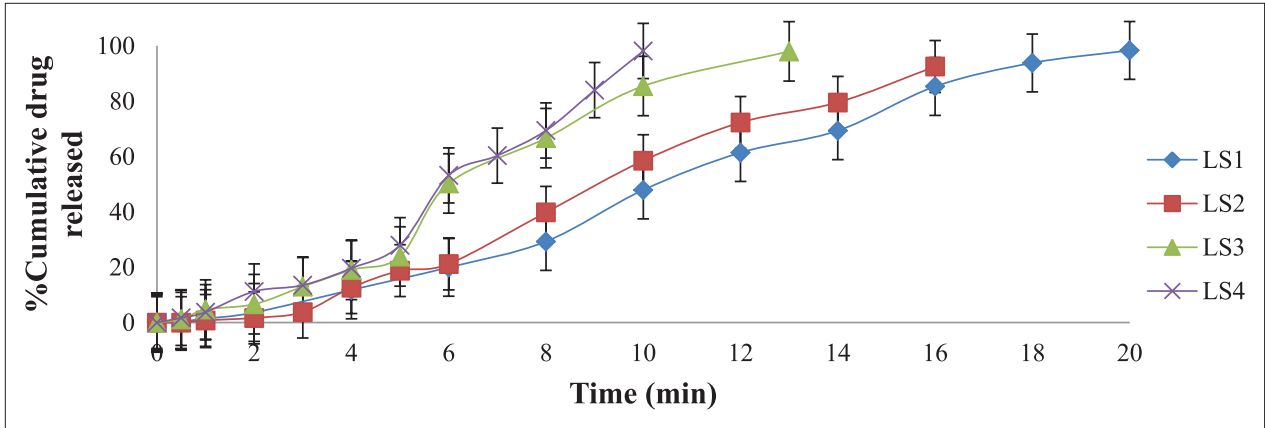

Fig. 13: In vitro dissolution profile of fast disintegrating tablet's prepared using Lepidium sativum. The data represent mean \pm standard of three determinations

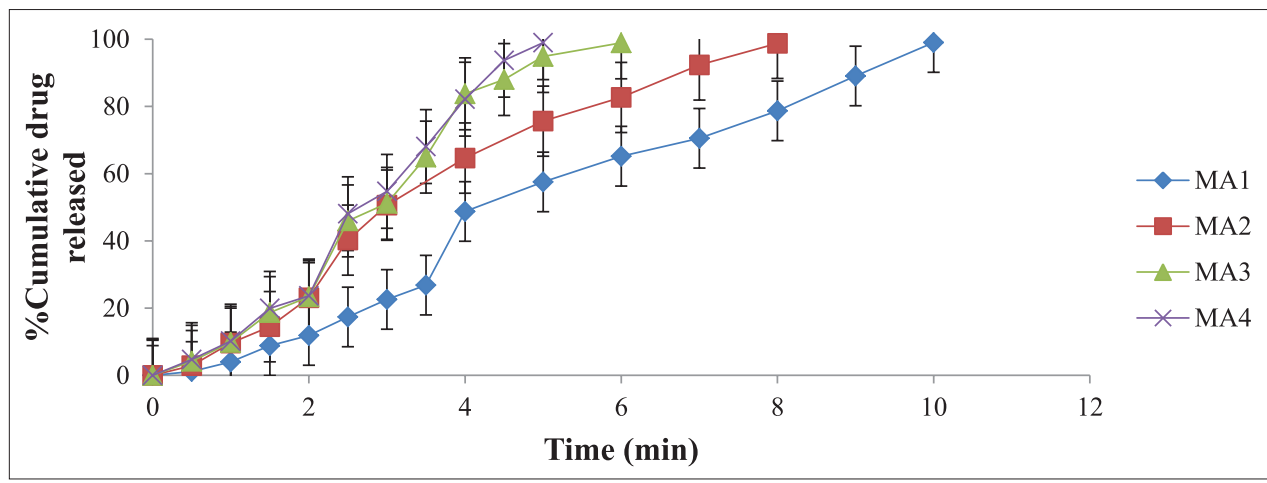

Fig. 14: In vitro dissolution profile of fast disintegrating tablet's prepared using malt agar. The data represent mean \pm standard of three determinations

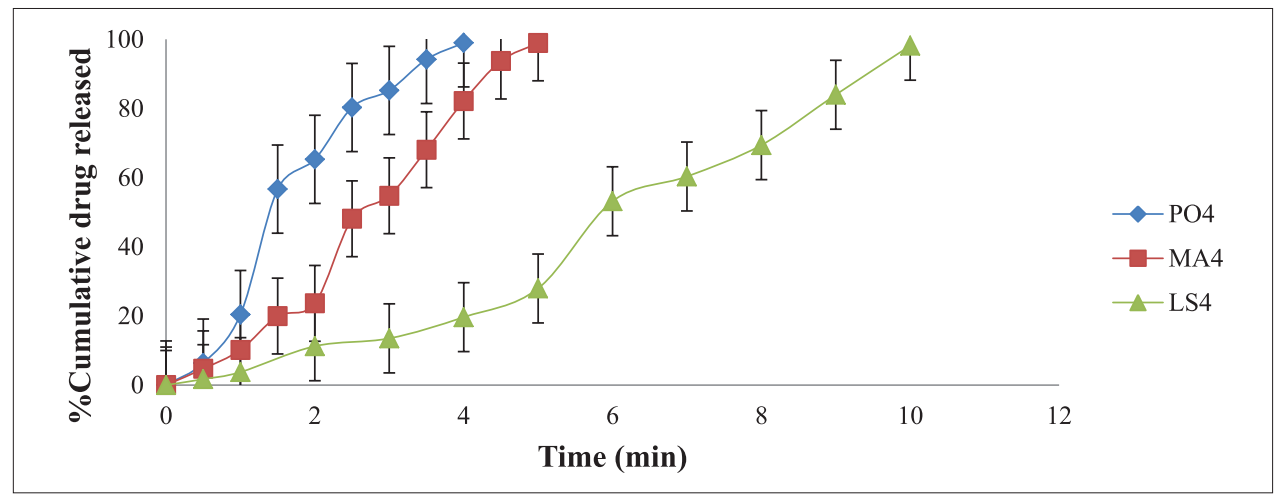

Fig. 15: Comparison of in vitro release profile of flurbiprofen fast disintegrating tablet's prepared using different superdisintegrants. The data represent mean \pm standard of three determinations 
Table 4: Stability study of flurbiprofen FDT PO4

\begin{tabular}{|c|c|c|c|c|}
\hline \multirow{2}{*}{$\begin{array}{l}\text { Formulation } \\
\text { code }\end{array}$} & \multicolumn{2}{|c|}{ Drug content* (mg) } & \multicolumn{2}{|l|}{ In vitro release* $(\%)$} \\
\hline & Before & After & Before & After \\
\hline $\mathrm{PO} 4$ & $99.00 \pm 0.13$ & $98.99 \pm 0.11$ & $98.98 \pm 0.53 / 4$ minutes & $98.22 \pm 0.74 / 4$ minutes \\
\hline
\end{tabular}

$*_{\mathrm{n}}=3$. FDT: Fast disintegrating tablet, PO4: Plantago ovate 4

\section{Stability study}

Stability studies were carried out with optimized FDT PO4 at $40 \pm 2^{\circ} \mathrm{C} / 75 \pm 5 \% \mathrm{RH}$ for the period of 6 months. The results indicated no significant changes in drug content and in vitro release (Table 4) indicating the FDT's remained fairly stable during stability period.

\section{CONCLUSION}

Flurbiprofen FDT's could be prepared with isolated natural superdisintegrants PO, LS and modified agar by direct compression method. All FDT's possessed good hardness, friability, compression, disintegration, and dissolution properties. FDT's disintegrated rapidly within the time limit. The tablets released the drug completely in short period which is advantageous for in vivo bioavailability. The natural superdisintegrants isolated showed promising results as superdisintegrants and can prove as effective alternative for synthetic disintegrants. The formulations prepared were found stable during the stability period.

\section{REFERENCES}

1. Indurwade NH, Rajyaguru TH, Nakhat PD. Novel approach-fas dissolving tablets. Indian Drugs 2002;39(8):405-9.

2. Bi Y, Yonezawa Y, Sunada H. Rapidly disintegrating tablets prepared by the wet compression method: Mechanism and optimization. J Pharm Sci 1999;88(10):1004-10.

3. Veerareddy PR, Vemula SK. Formulation, evaluation and pharmacokinetics of colon targeted pulsatile system of flurbiprofen. J Drug Target 2012;20(8):703-14.

4. Wang X, Yu J, Tang X. In vitro release and pharmacokinetics of flurbiprofen sustained release capsules containing coated pellets. Asian J Pharm Sci 2007;2(2):77-84.

5. Kaushik D, Dureja H, Saini TR. Mouth dissolving tablets: A review. Indian Drugs 2004;41(4):187-93.

6. Vemula SK, Veerareddy PR. Fast disintegrating tablets of flurbiprofen: Formulation and characterization. Lat Am J Pharm 2011;30(6):1135-41.

7. Mettu SR, Veerareddy PR. Formulation, evaluation and pharmacokinetics of flurbiprofen fast dissolving tablets. Br J Pharm Res 2013;3(4):617-31.

8. Patel JH, Tiwari P, Patel JS. Solid dispersion based tablets of poorly soluble drug flurbiprofen. Am J Pharmtech Res 2011;1(1):18-24.

9. Allen LV. Rapid-dissolve technology: An interview with Loyd V. Allen. Int J Pharm Technol 2003; 7:449-50

10. Fu Y, Yang S, Jeong SH, Kimura S, Park K. Orally fast disintegrating tablets: Developments, technologies, taste-masking and clinical studies. Crit Rev Ther Drug Carrier Syst 2004;21(6):433-76.

11. Babu GV, Kumar NR, Himasankar K, Seshasayana A, Murthy KV. Nimesulide-modified gum karaya solid mixtures: Preparation, characterization, and formulation development. Drug Dev Ind Pharm 2003;29(8):855-64.

12. Washi SP, Sharma VD, Jain VK, Sinha P. Plantago ovata genetic diversity, cultivation utilization and chemistry. Indian $\mathrm{J}$ Nat Prod 1985;1:3-6.

13. Hasegawa K, Mizutani J, Kosemura S, Yamamura S. Isolation and identification of lepidimoide, a new allelopathic substance from mucilage of germinated cress seeds. Plant Physiol 1992;100(2):1059-61.

14. Rao NN, Murthy BR, Rajasekhar D, Babu PS, Babu KP, Babu PS Design and development of amlodipine besylate fast dissolving tablets by using natural superdisintegrants. IJRPB 2013;1(2):175-9.

15. Ito A, Sugihara M. Development of oral dosage form for elderly patients: Use of agar as base of rapidly disintegrating oral tablets. Chem Pharm Bull (Tokyo) 1996;44(11):2132-6.

16. Fischer MH, Yu N, Gray GR, Ralph J, Anderson L, Marlett JA. The gel-forming polysaccharide of psyllium husk (Plantago ovata Forsk). Carbohydr Res 2004;339(11):2009-17.

17. Cooper J, Gunn C. Powder flow and compaction. In: Carter SJ, editor Tutorial Pharmacy. $6^{\text {th }}$ ed. New Delhi: CBS Publishers and Distributors; 1986. p. 211-33.

18. Shah D, Shah Y, Rampradhan M. Development and evaluation of controlled release diltiazem hydrochloride micro particles using cross linked poly vinyl alcohol. Drug Dev Ind Pharm 1997;23(6):567-74.

19. Aulton ME, Wells TI. Pharmaceutics. In: Aulton ME, editor. The Science of Dosage form Design. $3^{\text {rd }}$ ed. London: Churchill Livingstone; 1988. p. $355-467$

20. Rippie E. Compression of solids and compressed dosage forms. In Swarbrick J, editor. Encyclopaedia of Pharmaceutical Technology $3^{\text {rd }}$ ed. New York: Marcel Dekker Inc.; 1990. p. 149-66.

21. Chowdary KP, Hemavathy R. Formulation and dissolution rates studies on dispersible tablets of ibuprofen. Indian J Pharm Sc 2000;62(3):213-16.

22. Lachman L, Herbert A, Liberman S, Kamig JL. Tablets. In: Carter SJ, editor. The Theory and Practice of Industrial Pharmacy. $3^{\text {rd }}$ ed. Mumbai Varghese Publishing House; 1991. p. 300, 318, 370.

23. Martin A. Physical Pharmacy. $3^{\text {rd }}$ ed. Philadelphia, PA: Lea and Febiger; 1983.

24. Veerareddy PR, Vemula SK. Colon specific controlled release matrix tablets of flurbiprofen: Development and characterization. Asian J Pharm Clin Res 2012;5(4):92-6.

25. Bhagawati ST, Hiremath SN, Sreenivas SA. Comparative evaluation of disintegrants by formulating cefixime dispersible tablets. Indian J Pharm Educ Res 2005;39:194-7.

26. Doijad R, Manvi F, Khalandar K. A comparative study on mouth dissolving tablets of granisetron with different superdisintegrants Formulation and evaluation. IJPHARM 2008;5:26-34.

27. US Pharmacopeial Convention. US Pharmacopeia XXV. Rockville, MD: US Pharmacopeial Convention; 2002. p. 799-800.

28. Raghavendra Rao NG, Upendra K, Rao KD, Suresh DK. Formulation and evaluation of fast dissolving tablets of carbamazepine using natural superdisintegrant Plantago ovate seed powder and mucilage. Int J Pharm Pharm Sci 2010;2(2):70-4.

29. Aly A, Sermen M, Qato M. Super disintegrants for solid dispersion to produce rapidly disintegrating tenoxicam tablets via camphor sublimation. Pharm Technol 2005;29(1):68-78.

30. Sharma V, Arora V. Comparison of various natural superdisintegrants in the formulation of fast dissolving carvedilol tablet. Int J Pharm Sci Res 2012;3(10):3947-54.

31. Vikas S, Vandana A, Chanda R. Use of natural superdisintegrant in mouth dissolving tablet - An emerging trend. Int Bull Drug Res 2012;1(2):46-54.

32. Amal SM, El-Enin A. Flurbiprofen fast disintegrating tablets. Int J Pharm Pharm Sci 2014;6(2):499-505. 